\title{
Haemoparasites of free-roaming dogs associated with several remote Aboriginal communities in Australia
}

Emily N Barker ${ }^{1 *}$, Debra A Langton ${ }^{1}$, Chris R Helps ${ }^{2}$, Graeme Brown ${ }^{3}$, Richard Malik, Susan E Shaw ${ }^{1}$ and Séverine Tasker ${ }^{1}$

\begin{abstract}
Background: Tick-borne haemoparasites Babesia vogeli and Anaplasma platys are common among the free-roaming canine populations associated with Aboriginal communities in Australia, whilst the prevalence of haemoplasmas, which are also suspected to be tick-borne, remained unexplored. The aim of this study was to determine the prevalence of haemoplasma infection in these populations, and to identify any correlation with other haemoparasites. Blood was collected from 39 dogs associated with four Aboriginal communities and screened for infection using PCR and serology. DNA was purified and PCR analyses for piroplasms, Anaplasmataceae family bacteria and haemoplasmas performed. Serum was analysed using a commercial haemoparasite ELISA. Prevalence of infection was compared between communities.

Results: Seventeen dogs (44\%) were infected (PCR positive) with Mycoplasma haemocanis, eight (21\%) with 'Candidatus Mycoplasma haematoparvum', 20 (51\%) with A. platys, and 17 (44\%) with B. vogeli. Two dogs were infected with a novel haemoplasma as determined by DNA amplification and sequencing. Two dogs (5\%) were serologically positive for Dirofilaria immitis antigens, one (3\%) was positive for Ehrlichia canis antibodies and nine (24nbsp;\%) were positive for A. platys antibodies. Co-infections were frequent. Haemoplasma prevalence was highest $(73 \%, 16 / 22)$ in Central Australia and lowest $(22 \%, 2 / 9)$ in Western Australia ( $p=0.017)$. In contrast, B. vogeli prevalence was low in Central Australia $(18 \%, 4 / 22)$ but higher $(78 \%, 7 / 9)$ in Western Australia $(p=0.003)$.

Conclusions: This is the first time haemoplasma infections, including a novel species, have been molecularly documented in Australian dogs. The wide regional variation in prevalence of some of the haemoparasite infections detected in this study warrants further investigation.
\end{abstract}

\section{Background}

Dogs associated with the Aboriginal communities in the remote regions of Australia are considered to be freeroaming as they are owned but not confined in any manner. Amongst this canine population, infestation with the brown dog tick (Rhipicephalus sanguineus) is endemic and infections with Anaplasma platys and Babesia vogeli, tick-borne haemoparasites associated with $R$. sanguineus, are widespread [1]. The canine haemoplasmas Mycoplasma haemocanis and 'Candidatus Mycoplasma haematoparvum' are also believed to have $R$. sanguineus-

\footnotetext{
* Correspondence: emi.barker@bristol.ac.uk

${ }^{1}$ School of Veterinary Sciences, University of Bristol, Langford, Bristol BS40 5DU, UK

Full list of author information is available at the end of the article
}

mediated transmission [2], with free-roaming behaviour suspected of being a significant risk factor for the relatively high haemoplasma prevalence $(20 \%)$ in Tanzanian dogs [3]. A recent PCR-based study of a canine hospital population in Sydney, New South Wales did not identify any haemoplasma infections (N. Hetzle, personal communication), although the blood was collected from non free-roaming owned dogs in a large city where the brown dog tick is very rarely found.

The aim of this study was to determine the prevalence of canine haemoplasma infections in free-roaming dogs from several remote Aboriginal communities (see Figure 1), Ti Tree (Nturiya and Pmara) in the Northern Territory (Central Australia), Tiwi Islands (off the coast of the Northern Territory), Goodooga (north-western New South

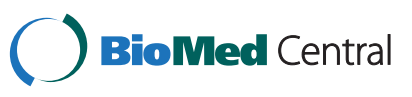




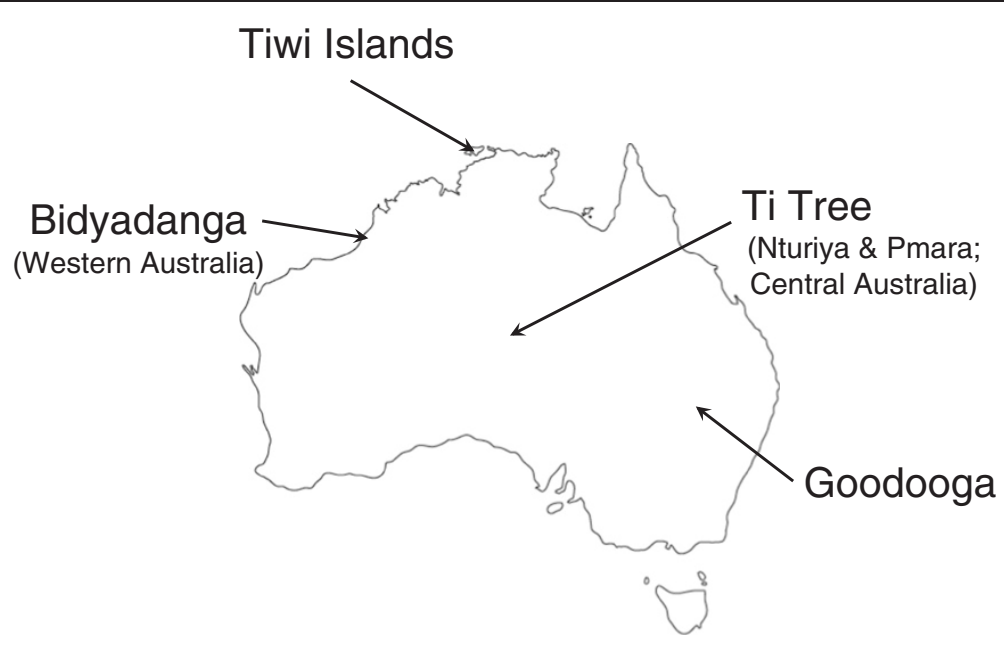

Figure 1 Map of Australia with sampling sites indicated.

Wales) and Bidyadanga (Western Australia), using realtime quantitative PCR analysis. A further aim was to determine if such infections were associated with other haemoparasites.

\section{Results}

\section{Population}

Of the 39 dogs sampled, 20 were male and 19 were female (Table 1). Most of the dogs were entire. The majority of dogs were adults $(n=25)$, with equal numbers $(n=7)$ of puppies and juvenile dogs.

\section{PCR Results}

PCR results were available for all samples for all assays. DNA was successfully purified and amplified from all canine blood samples as determined by the presence of adequate levels of canine internal control gene glyceraldehyde 3-phosphate dehydrogenase (GAPDH; threshold cycle: 18.2 to 23.3).
See Table 1 for a complete breakdown of results for each region (See Additional file 1: Table S1 for results of individual dog). Of the 39 dogs, 17 (44\%) were infected, as determined by a positive quantitative PCR (qPCR) result, with $M$. haemocanis (threshold cycle: 22.3 to 38.2 ) and eight (21\%) with 'Ca. M. haematoparvum' (threshold cycle: 27.2 to 35.2 ). Twenty dogs (51\%) were infected with A. platys (threshold cycle: 24.4 to 41.3 ) as determined by qPCR, 16 of these dogs were also positive using the Anaplasmataceae family conventional PCR (cPCR). No samples were positive by the Anaplasmataceae family CPCR and negative by the $A$. platys qPCR. Amplicons from two positive samples using the Anaplasmataceae family $\mathrm{cPCR}$ assay were confirmed by sequencing to contain $A$. platys DNA. Seventeen (44\%) of the 39 dogs were positive, as determined by cPCR, for a Babesia/Theileria spp. piroplasm. Amplicon sequencing of 15 of the 17 positive results indicated the presence of $B$. vogeli (insufficient

Table 1 Population data, PCR and A. platys serological results for each Aboriginal community

\begin{tabular}{|c|c|c|c|c|c|c|c|c|}
\hline \multirow[b]{2}{*}{$\begin{array}{l}\text { Aboriginal } \\
\text { community }\end{array}$} & \multicolumn{3}{|c|}{ Population } & \multicolumn{4}{|c|}{ PCR } & \multirow{2}{*}{$\begin{array}{l}\text { Serology } \\
\begin{array}{l}\text { Anaplasma } \\
\text { platys }\end{array}\end{array}$} \\
\hline & $\begin{array}{l}\text { Dogs } \\
\text { sampled }\end{array}$ & $\begin{array}{l}\text { Age (puppy / } \\
\text { juvenile / adult) }\end{array}$ & $\begin{array}{l}\text { Gender } \\
(\mathrm{M} / \mathrm{F})\end{array}$ & $\begin{array}{l}\text { Mycoplasma } \\
\text { haemocanis }\end{array}$ & $\begin{array}{l}\text { 'Ca. Mycoplasma } \\
\text { haematoparvum' }\end{array}$ & $\begin{array}{l}\text { Anaplasma } \\
\text { platys }\end{array}$ & Babesia vogeli & \\
\hline Ti Tree ${ }^{\S}:$ & 22 & $1 / 5 / 16$ & $13 / 9$ & $14(63.6 \%)^{*}$ & $7(31.8 \%)^{*}$ & $8(36.4 \%)$ & $4(18.2 \%)$ & $5(23.8 \%)$ \\
\hline Nturiya $^{\dagger}$ & 11 & $0 / 3 / 8$ & $8 / 3$ & 5 (45.5\%) & $3(27.3 \%)$ & 4 (36.4\%) & 1 (9.1\%) & 1 (9.1\%) \\
\hline Pmara & 11 & $1 / 2 / 8$ & $5 / 6$ & $9(81.8 \%)$ & $4(36.4 \%)$ & $4(36.4 \%)$ & $3(27.3 \%)$ & $4(40.0 \%)^{\#}$ \\
\hline Tiwi Islands & 3 & $0 / 1 / 2$ & $1 / 2$ & $1(33.3 \%)$ & $0(0 \%)$ & $3(100 \%)$ & $3(100 \%)$ & 1 (33.3\%) \\
\hline Goodooga & 5 & $1 / 0 / 4$ & $2 / 3$ & $1(20.0 \%)$ & $1(20.0 \%)$ & $2(40.0 \%)$ & $3(60.0 \%)$ & $0(0 \%)$ \\
\hline Bidyadanga $^{\dagger}$ & 9 & $5 / 1 / 3$ & $4 / 5$ & $1(11.1 \%)$ & $0(0 \%)$ & $7(77.8 \%)$ & 7 (77.8\%) & $3(33.3 \%)$ \\
\hline Total & 39 & $7 / 7 / 25$ & $20 / 19$ & 17 (43.6\%) & $8(20.5 \%)$ & 20 (51.3\%) & 17 (43.6\%) & 9 (23.7\%) \\
\hline
\end{tabular}

The number (and percentages, in parentheses) of dogs infected with each haemoparasite is recorded.

$\S$ The Ti Tree results are the sum of those from Nturiya and Pmara.

*Six dogs were co-infected with both $M$. haemocanis and 'Ca. M. haematoparvum'.

${ }^{\dagger}$ The novel haemoplasma was detected in two dogs: one from Nturiya (Ti Tree) and one from Bidyadanga.

\#Data available for 10 of the 11 dogs. 
amplification of target DNA from the remaining two positive samples resulted in a failure to sequence).

All dogs positive for $M$. haemocanis and/or ' $\mathrm{C} a$. M. haematoparvum' were also positive by the panhaemoplasma assay, but two additional dogs were positive only on the pan-haemoplasma assay (threshold cycle: 36.7 \& 37.9), corresponding to approximately one to ten haemoplasmas per reaction (equivalent to $5 \mu \mathrm{l}$ DNA template); one from Nturiya ( $\mathrm{Ti}$ Tree) and one from Bidyadanga. Of these dogs, one was negative for all other haemoparasites, and the other was positive for $A$. platys and B. vogeli. Sequencing of a $600 \mathrm{bp} 16 \mathrm{~S}$ rRNA gene fragment amplified from these discordant samples showed that they were both infected with the same novel haemoplasma species [EMBL:HE577612] (Figure 2: phylogenetic tree). The novel haemoplasma had highest identity ( 82.8 to $84.9 \%)$ to the haemofelis group of haemoplasmas [4], closely followed by the haemominutum group of haemoplasmas (79.1 to $83.7 \%$ ) and the nonhaemotropic mycoplasmas Mycoplasma fastidiosum and Mycoplasma cavipharyngis (82.3 and $82.5 \%$ respectively). The 23 bp deletion common to haemofelis group haemoplasmas was not present in the novel haemoplasma gene sequence. Attempts to amplify a larger $16 \mathrm{~S}$ rRNA gene fragment and a ribonuclease $\mathrm{P}$ ribosomal gene fragment from these two samples were unsuccessful.

\section{Serology}

Serological results were available for all dogs, except for an A. platys antibody result for the only dog (from Pmara, Ti Tree) that was positive for E. canis antibodies. Nine dogs (23.7\%) were positive for A. platys antibodies (Table 1 ). Both dogs that were serologically positive for $D$. immitis antigen were from Nturiya. No dogs were positive for B. burgdorferi antibodies.

\section{Co-infections \& concurrent seropositive results}

Six of the dogs in Ti Tree were infected with both $M$. haemocanis and ' $\mathrm{Ca}$. M. haematoparvum', whilst coinfection with $\mathrm{M}$. haemocanis and ' $\mathrm{Ca}$. M. haematoparvum' was not present in the other communities. Six of the haemoplasma positive dogs were infected with $A$. platys as determined by qPCR: one was infected with $M$. haemocanis alone; two with ' $\mathrm{Ca}$. M. haematoparvum' alone; two co-infected with $\mathrm{M}$. haemocanis and ' $\mathrm{Ca}$. M. haematoparvum'; and a further dog infected with the novel haemoplasma. Six dogs positive for B. vogeli, as determined by $\mathrm{CPCR}$, were positive for one or more 
haemoplasma: three with $M$. haemocanis alone; one with 'Ca. M. haematoparvum' alone; one co-infected with $M$. haemocanis and 'Ca. M. haematoparvum'; and a further dog with the novel haemoplasma. Three dogs infected with $M$. haemocanis, one of which was co-infected with 'Ca. M. haematoparvum', were seropositive for A. platys. One dog co-infected with $M$. haemocanis and ' $C a$. M. haematoparvum' was also seropositive for $D$. immitis antigen.

Of the 20 dogs infected with $A$. platys as determined by qPCR, 13 were cPCR-positive for $B$. vogeli, six were seropositive for $A$. platys antibodies (one dog had an unknown result), one was seropositive for $E$. canis antibodies, and one was seropositive for $D$. immitis antigen.

Of the 17 dogs infected with $B$. vogeli as determined by cPCR, five were seropositive for $A$. platys antibodies (one unknown), one was serpositive for $E$. canis antibodies, and none were seropositive for $D$. immitis antigen.

The dog that was seropositive for $E$. canis antibodies was also PCR positive for $A$. platys, B. vogeli, M. haemocanis and 'Ca. M. haematoparvum'.

\section{Comparisons between aboriginal communities}

Due to the low numbers of dogs from each community, only haemoparasite prevalences from Central Australia (Ti Tree) and Western Australia (Bidyadanga) could be compared. Haemoplasma prevalence was highest (16/22; $73 \%)$ in Central Australia and lowest $(2 / 9 ; 22 \%)$ in Western Australia. The difference in haemoplasma prevalence between these two sites was statistically significant $(\mathrm{p}=0.017$; Fisher's exact test). In contrast, B. vogeli prevalence was low in Central Australia (4/22; 18\%) but higher $(6 / 9 ; 66 \%)$ in Western Australia. The difference in $B$. vogeli prevalence between these two sites was statistically significant ( $\mathrm{p}=0.003$; Fisher's exact test). There was a trend towards a statistically significant difference in $A$. platys prevalence between Central Australia (8/22; $36 \%$ ) and Western Australia (7/9; 78\%; p = 0.054; Fisher's exact test).

\section{Discussion}

Prevalence of the haemoparasites A. platys and B. vogeli in this report was higher $(51.3 \%$ \& $43.6 \%$ respectively; $33.3 \%$ dual $A$. platys \& B. vogeli infection) than in earlier studies of a similar population of free-roaming dogs associated with Aboriginal communities, where 43\% were positive for $A$. platys and $21 \%$ for B. vogeli, including $11 \%$ dual infections [1]. The study [1] also reported marked regional variation, with $A$. platys infection ranging from 39\% in north-western New South Wales (including the Goodooga community) to $50 \%$ in coastal Arnhem Land in the Northern Territory (near the Tiwi Islands) and B. vogeli infection ranging from $9 \%$ in the Northern Territory to $29 \%$ in the Tanami desert (approximately half way between the Tiwi Islands and $\mathrm{Ti}$ Tree communities).

Canine haemoplasma prevalence outside of Australia has ranged from $0 \%$ in the UK [5] to $40 \%$ in Sudan [6], with higher prevalences tending to be seen in warmer climates. This compares to a haemoplasma prevalence rate of $54 \%$ in the free-roaming canine population described in this study. Mycoplasma haemocanis prevalence has been reported to be up to $40 \%$ [7] and 'Ca. M. haematoparvum' prevalence up to $33 \%$ [6] with co-infections identified in up to $17 \%$ of haemoplasma positive dogs [8], compared to figures of $44 \%, 21 \%$ and $32 \%$, respectively from the present study. It was not possible to determine whether dogs in this study were coinfected with a $M$. haemocanis or ' $\mathrm{Ca}$. M. haematoparvum' and the novel haemoplasma due to the methodology. In the authors' opinion the less than $85 \%$ identity to known Mycoplasma species and the absence of the characteristic deletion common to the most closely related haemofelis group of haemoplasmas are sufficient to be able to describe the haemoplasma identified as being novel [9]. Unfortunately, copy numbers of the novel haemoplasma within the blood of both dogs identified as being infected were too low to enable molecular description sufficient to name the novel species. The significance and the primary host of the novel haemoplasma have yet to be determined.

Canine heartworm has been reported in domestic dogs in Southern Australia and dingoes in the Northern Territories, so the detection of $D$. immitis antigen was not unexpected $[10,11]$. It is uncertain and controversial as to whether Lyme borreliosis occurs in Australia [12]. Currently, there is no evidence that B. burgdorferi is responsible for a local syndrome, which has clinical features reminiscent of Lyme disease, so absence of seropositivity in dogs was to be expected. The positive serological result for E. canis could not be confirmed by Anaplasmataceae family cPCR, as the dog was also positive for $A$. platys by qPCR. In addition, false positive results for $E$. canis antibody tests have previously been reported in Australia, indicating the presence of crossreacting antibodies [13], raising the suspicion of a false positive result in this case, however, exposure or coinfection with a low copy number of $E$. canis organisms could not be ruled out.

Inferences from the statistical analysis were limited by the small number of samples obtained in some of the Aboriginal communities, which in turn were limited by a short time-frame for sample collection, and the freeroaming nature of the dogs. It is hoped that future studies involving haematological analyses in conjunction with PCR-based detection of haemoparasites from a larger number of dogs from a single community will elucidate the potential role of canine haemoplasma infection 
and disease, as both $A$. platys and $B$. vogeli have been associated with a reduction in mean platelet numbers [1] while anaemia has been associated only with $B$. vogeli. The role of haemoplasmas and their mode of transmission in this setting need to be ascertained to determine whether interventions with antimicrobial and / or ectoparasiticidal agents are appropriate. Identification of additional animals infected with a greater copy number of the novel haemoplasma would be required to enable further characterisation and complete molecular description. A much greater number of samples from Tiwi Islands, Goodooga and Bidyadanga would be required to accurately assess the prevalence of $D$. immitis infection in these populations.

\section{Conclusions}

Dogs living in aboriginal communities represent a naturally occurring model of polymicrobial haemoparasitic infection. Similar to $A$. platys and B. vogeli infection, haemoplasma infection, either with single species or coinfections was common in the free-roaming canine populations associated with Aboriginal communities. The wide variation in regional infection prevalence between some of the haemoparasite infections warrants further investigations to determine the role of vectors in disease transmission and the influence of concurrent haemoparasite infections on susceptibility and pathogenicity, especially in relation to the occurrence of anaemia and thrombocytopenia.

\section{Methods \\ Samples}

EDTA-blood and whole blood (clot tube) were collected from 39 free-roaming dogs associated with four Aboriginal communities, between February 2008 and October 2009. Blood was stored at $4^{\circ} \mathrm{C}$, and transported to the laboratory within seven days of collection. Serum was harvested from whole blood after centrifugation. EDTA blood and serum were subsequently frozen at $-70^{\circ} \mathrm{C}$ until required.

Most dogs were of mixed breed, and were considered variable hybrids of the dingo (Canis lupus dingo) and the domestic dog (Canis lupus familiaris). Based on dentition they were assigned to three age classes: puppy ( $<3$ months), juvenile ( 3 to 12 months) and adult (> 12 months).

\section{DNA extraction and PCR analysis}

DNA was purified from the samples using the QIAmp ${ }^{\circledR}$ DNA Mini Kit (Qiagen Pty Ltd) according to the manufacturer's recommendations, then shipped to the UK on dry ice.

Purified DNA was subjected to an Anaplasmataceae family conventional PCR cPCR and a Babesia / Theileria spp. cPCR. The Anaplasmataceae family cPCR comprised a primer pair (EHR16SD GGTACCYACAGAAGAAGTCC \& EHR16SR TAGCACTCATCGTTTACAGC) [14], which amplifies a 345 base pair (bp) fragment from the $16 \mathrm{~S}$ rRNA gene using the following thermal protocol: $95^{\circ}$ $\mathrm{C}$ for $10 \mathrm{~min}$ and 40 cycles of $95^{\circ} \mathrm{C}$ for $30 \mathrm{~s}, 55^{\circ} \mathrm{C}$ for $30 \mathrm{~s}$, and $72^{\circ} \mathrm{C}$ for $30 \mathrm{~s}$. The Babesia/Theileria spp. cPCR comprised a primer pair (BabgenF GAAACTGCGAATGGCTCATTA \& BabgenR CGGTAGGCCAATACCCTACCGTC) [15], which amplifies a 250-270 bp fragment from the $18 \mathrm{~S}$ rRNA gene using the following thermal protocol: $94^{\circ} \mathrm{C}$ for $10 \mathrm{~min}$ and 40 cycles of $94^{\circ} \mathrm{C}$ for $30 \mathrm{~s}$, $65^{\circ} \mathrm{C}$ for $30 \mathrm{~s}$, and $72^{\circ} \mathrm{C}$ for $45 \mathrm{~s}$. All reactions used $2 \mathrm{x}$ HotStarTaq Master Mix (Qiagen, Crawley, UK) with $200 \mathrm{nM}$ each primer pair, $3.0 \mathrm{mM}$ final $\mathrm{MgCl}_{2}$ and $2 \mu \mathrm{L}$ DNA template in a total volume of $20 \mu \mathrm{L}$, and were performed in a Tetrad thermal cycler (MJ Research, Waltham, MA, USA). Positive and negative control reactions were used in each assay. Amplification products were visualised on an agarose gel following electrophoretic separation.

Purified DNA was also subjected to the following qPCR assays: species-specific qPCRs for each of $M$. haemocanis and ' $\mathrm{Ca}$. M. haematoparvum', each duplexed with a GAPDH qPCR [3], pan-haemoplasma qPCRs [16], and an A. platys-specific qPCR (personnel communication: $\mathrm{M}$ Robinson, Acarus Laboratory, University of Bristol). Briefly, the canine species-specific qPCRs were performed using 2x HotStarTaq Master Mix with $200 \mathrm{nM}$ species-specific haemoplasma $16 \mathrm{~S}$ rRNA gene primer pair (M. haemocanis: Mhf 1167 F GTGCTACAATGGCGAACACA \& Mhf 1246R TCCTATCCGAACTGAGACGAA; 'Ca. M. haematoparvum': CMhp 124 F GGAGAATAGCAATCCGAAAGG \& CMhp 252R GCATTTACCCCACCAACAAC), $100 \mathrm{nM}$ haemoplasma TaqMan probe (M. haemocanis: Mhf 1188 T FAM-TGTGTTGCAAACCAGCGATGGT-BHQ1; 'Ca. M. haematoparvum': CMhp 192 T FAM-CTTCGGGAGCCCCGCGC-BHQ1), $25 \mathrm{nM}$ canine GAPDH gene primer pair (17 F TCAACGGATTTGGCCGTATTGG \& 106R TGAAGGGGTCATTGATGGCG), $50 \mathrm{nM}$ canine GAPDH TaqMan probe (TXR-CAGGGCTGCTTTTAACTCTGGCAAAGTGGA$B H Q 2), 4.5 \mathrm{mM}$ final $\mathrm{MgCl}_{2}$ and $5 \mu \mathrm{l}$ gDNA in a total volume of $25 \mu \mathrm{l}$. Briefly, the pan-haemoplasma qPCRs were performed using 2x HotStarTaq Master Mix with $200 \mathrm{nM}$ haemoplasma $16 \mathrm{~S}$ rRNA gene primer pair (Haemofelis group: HF grp 567 F GGAGCGGTGGAATGTGTAG \& HF grp 680R GGGGTATCTAATCCCATTTGC; Haemominutum group: HM grp 1061 F GGGGCCAAGTCAAGTCATC \& HM grp 1199R GCGAATTGCAGCCTTTTATC), $100 \mathrm{nM}$ haemoplasma TaqMan probe (Haemofelis group: HF grp 595P FAM-TYAAGAACACCAGAGGCGAAGGCG-BHQ1; Haemominutum group: HM grp 1096P FAM-TACCATTGTAGCACGTTYGCAGCCC-BHQ1), $4.5 \mathrm{mM}$ final $\mathrm{MgCl}_{2}$ and $5 \mu \mathrm{l}$ gDNA in a 
total volume of $25 \mu \mathrm{l}$. All haemoplasma qPCRs were performed in an Agilent MX3005P real-time PCR machine (Agilent Technologies UK Ltd., Wokingham, UK): $95^{\circ} \mathrm{C}$ for $15 \mathrm{~min}$ and 45 cycles of $95^{\circ} \mathrm{C}$ for $10 \mathrm{~s}$ and $60^{\circ} \mathrm{C}$ for $30 \mathrm{~s}$, during which fluorescence data were collected. Briefly, the $A$. platys-specific qPCRs were performed using 2x HotStarTaq Master Mix (Qiagen, Crawley, UK) with $200 \mathrm{nM} \mathrm{A}$. platys-specific citrate synthase gene $(g l t A)$ primer pair (APLgltA1.f AGGCGTGATTTCATCCTTCA \& APLgltA1.r CACAGCAAGCTCTTCATTTCC), $100 \mathrm{nM}$ gltA TaqMan probe (APLgltA1.p FAM-TGGCTGCGA- A GTATCATGGGGA-BHQ1), $5.0 \mathrm{mM}$ final $\mathrm{MgCl}_{2}$ and $5 \mu \mathrm{l}$ gDNA in a total volume of $25 \mu$ l. All reactions were performed in an Opticon (Bio-Rad Labs. Ltd., Hemel Hempstead, UK) real-time PCR machine: $95^{\circ} \mathrm{C}$ for $15 \mathrm{~min}$ and 45 cycles of $95^{\circ} \mathrm{C}$ for $10 \mathrm{~s}$ and $64^{\circ} \mathrm{C}$ for $15 \mathrm{~s}$, during which fluorescence data were collected. Positive and negative control reactions were used in each assay. Samples with discordant haemoplasma results (generic assay positive but $M$. haemocanis \& ' $C a$. M. haematoparvum' negative) were subjected to CPCR amplification using $2 \mathrm{x}$ HotStarTaq Master Mix, $200 \mathrm{nM}$ of a universal Mycoplasma primer pair (HBT-F ATACGGCCCATATT- CC TACG \& HBT-R TGCTCCACCACTTGTTCA) [17], $3.75 \mathrm{mM}$ final $\mathrm{MgCl}_{2}$ and $5 \mu \mathrm{L}$ DNA template in a total volume of $25 \mu \mathrm{L}$, using the following thermal protocol: $95^{\circ} \mathrm{C}$ for $15 \mathrm{~min}$ and 50 cycles of $95^{\circ} \mathrm{C}$ for $10 \mathrm{~s}, 55^{\circ} \mathrm{C}$ for $15 \mathrm{~s}$ and $72^{\circ} \mathrm{C}$ for $30 \mathrm{~s}$ in a MJ Mini thermal cycler (Bio-Rad Labs. Ltd.).

Amplicons from positive cPCR results were purified using the NucleoSpin ${ }^{\circledR}$ Extract II Kit (Macherey-Nagel, ABgene, Epsom, UK), and subjected to DNA sequencing using Applied Biosystems Big-Dye Ver 3.1 chemistry on an Applied Biosystems model 3730 automated capillary DNA sequencer. BLASTn analysis [18] was performed to compare the $16 \mathrm{~S}$ rRNA gene (Anaplasmataceae family \& haemoplasmas) and $18 \mathrm{~S}$ rRNA gene (Babesial Theileria spp.) sequences obtained to those in GenBank. A phylogenetic tree including existing haemoplasma species, as well as selected non-haemoplasma Mycoplasma species, was constructed using MacVector version 12 (MacVector, Inc., Cambridge, United Kingdom) for the $16 \mathrm{~S}$ rRNA gene using the neighbour-joining program from a distance matrix [19], corrected for nucleotide substitutions by the Kimura two-parameter model [20]. The data set was re-sampled 1000 times to generate bootstrap percentages. The $16 \mathrm{~S}$ rRNA gene fragment of the novel haemoplasma species was deposited in the European Molecular Biology Laboratory Nucleotide Database (HE577612).

\section{Serology}

Serum samples were tested by enzyme-linked immunosorbent assay (ELISA) for Dirofilaria immitis (heartworm) antigen and Ehrlichia canis, Borrelia burgdorferi, Anaplasma phagocytophilum antibodies using the SNAP 4Dx kit (Idexx Laboratories Pty. Ltd., Rydalmere, NSW 2116, Australia). Due to cross reactivity between $A$. platys- and A. phagocytophilum-directed antibodies, in conjunction with the absence of $A$. phagocytophilum from Australia, a positive A. phagocytophilum ELISA result was taken to indicate exposure to A platys (Personal Communication: Idexx Laboratories Pty. Ltd.).

\section{Statistical analysis}

Data were entered into Microsoft ${ }^{\circledR}$ Office Excel ${ }^{\circledR} 2007$ (Microsoft Corporation) and statistical analyses performed using Statistical Package for the Social Sciences version 18.0 (SPSS Inc., Chicago, IL). Categorical data, i. e. absence or presence of specific infection, gender, age, Aboriginal community ( $\mathrm{Ti}$ Tree \& Bidyadanga only), were compared using the chi-square test, or the Fisher's exact test where sample sizes were small. Too few dogs were available from Tiwi Islands and Goodooga to allow statistical evaluation of area influence on infection. Insufficient numbers were available in each category to enable multivariate analysis. Significance was taken as $\mathrm{p} \leq 0.05$.

\section{Animal ethics}

All procedures were performed with the approval of the Animal Ethics committee of the University of Sydney (N00/11-2006/3/4492).

\section{Additional file}

Additional file 1: Table S1. For individual dogs: population data (Aboriginal community; age; sex); Babesia vogeli (Bv) conventional PCR (CPCR) results [positive or not-detected (n/d)], Anaplasma platys (Ap), 'Candidatus Mycoplasma haematoparvum' (CMhp) and Mycoplasma haemocanis (Mhc) quantitative PCR (qPCR) results [threshold cycle for positive samples or not-detected (n/d)]: Dirofilaria immitis (Di), Borrelia burgdorferi (Bb), Ehrlichia canis (Ec), and A. platys (Ap) serological results.

\section{Authors' contributions}

GB, RM, SS and ST conceived of the study. GB and RM collected the samples and performed the ELISAs. ENB, DL and CRH carried out the PCR screening assays, DNA sequencing and analysis. ENB, CRH and ST drafted the manuscript. All authors read and approved the final manuscript.

\section{Acknowledgements}

We thank Anne and Chris Brown for helping with the collection of blood samples. The work was supported by a linkage grant from the Australian Research Council. ENB was supported by a University of Bristol Postgraduate Research Scholarship and Pfizer Health Limited. Data from this study were presented by ENB in abstract form at the $21^{\text {st }}$ European College of Veterinary Internal Medicine - Companion Animal Annual Congress, Seville, Spain in September 2011

\section{Author details}

${ }^{1}$ School of Veterinary Sciences, University of Bristol, Langford, Bristol BS40 5DU, UK. ${ }^{2}$ Langford Veterinary Services, University of Bristol, Langford, Bristol BS40 5DU, UK. ${ }^{3}$ Faculty of Veterinary Science, University of Sydney ", B14, NSW, 
Sydney, 2006, Australia. ${ }^{4}$ Centre for Veterinary Education, University of Sydney, SydneyB22, NSW, 2006, Australia.

Received: 1 December 2011 Accepted: 17 April 2012

Published: 14 May 2012

\section{References}

1. Brown GK, Canfield PJ, Dunstan RH, Roberts TK, Martin AR, Brown CS, Irving R: Detection of Anaplasma platys and Babesia canis vogeli and their impact on platelet numbers in free-roaming dogs associated with remote Aboriginal communities in Australia. Aust Vet J 2006, 84(9):321-325.

2. Seneviratna P, Weerasinghe N, Ariyadasa S: Transmission of Haemobartonella canis by dog tick, Rhipicephalus sanguineus. Res Vet SCi 1973, 14(1):112-114.

3. Barker EN, Tasker S, Day MJ, Warman SM, Woolley K, Birtles RJ, Georges K, Ezeokoli CD, Newaj-Fyzul A, Campbell M, et al: Development and use of real-time PCR to detect and quantify Mycoplasma haemocanis and "Candidatus Mycoplasma haematoparvum" in dogs. Vet Microbiol 2010, 140(1-2):167-170.

4. Peters IR, Helps CR, McAuliffe L, Neimark H, Lappin MR, Gruffydd-Jones TJ, Day MJ, Hoelzle K, Willi B, Meli ML, et al: RNaseP RNA gene $(r n p B)$ phylogeny of mycoplasmas and other Mycoplasma species. J Clin Microbiol 2008, 46(5):1873-1877.

5. Warman SM, Helps CR, Barker EN, Day S, Sturgess K, Day MJ, Tasker S: Haemoplasma infection is not a common cause of canine immunemediated haemolytic anaemia in the UK. J Small Anim Pract 2010, 51(10):534-539.

6. Inokuma H, Oyamada M, Davoust B, Boni M, Dereure J, Bucheton B, Hammad A, Watanabe M, Itamoto K, Okuda M, et al: Epidemiological survey of Ehrlichia canis and related species infection in dogs in eastern Sudan. Ann N Y Acad Sci 2006, 1078:461-463.

7. Novacco M, Meli ML, Gentilini F, Marsilio F, Ceci C, Pennisi MG, Lombardo G, Lloret A, Santos L, Carrapico T, et al: Prevalence and geographical distribution of canine hemotropic mycoplasma infections in Mediterranean countries and analysis of risk factors for infection. Vet Microbiol 2010, 142(3-4):276-284.

8. Kenny MJ, Shaw SE, Beugnet F, Tasker S: Demonstration of two distinct hemotropic mycoplasmas in French dogs. J Clin Microbiol 2004, 42(11):5397-5399.

9. Drancourt M, Raoult D: Sequence-based identification of new bacteria: a proposition for creation of an orphan bacterium repository. J Clin Microbiol 2005, 43(9):4311-4315.

10. Starr TW, Mulley RC: Dirofilaria immitis in the dingo (Canis familiaris dingo) in a tropical region of the Northern Territory, Australia. J Wild Dis 1988, 24(1):164-165.

11. Copland MD, O'Callaghan MG, Hajduk P, O'Donoghue PJ: The occurrence of Dirofilaria immitis in dogs in South Australia. Aust Vet J 1992, 69(2):31-32

12. Russell RC: Lyme disease in Australia - still to be proven!. Emerg Infect Dis 1995, 1(1):29-31.

13. Mason RJ, Lee JM, Curran JM, Moss A, Van Der Heide B, Daniels PW: Serological survey for Ehrlichia canis in urban dogs from the major population centres of northern Australia. Aust Vet J 2001, 79(8):559-562.

14. Parola P, Roux V, Camicas JL, Baradji I, Brouqui P, Raoult D: Detection of Ehrlichiae in African ticks by polymerase chain reaction. Trans $R$ Soc Trop Med Hyg 2000, 94(6):707-708.

15. Baneth G, Kenny MJ, Tasker S, Anug Y, Shkap V, Levy A, Shaw SE: Infection with a proposed new subspecies of Babesia canis, Babesia canis subsp. presentii, in domestic cats. J Clin Microbiol 2004, 42(1):99-105.

16. Tasker S, Peters IR, Mumford AD, Day MJ, Gruffydd-Jones TJ, Day S, Pretorius A-M, Birtles RJ, Helps CR, Neimark H: Investigation of human haemotropic Mycoplasma infections using a novel generic haemoplasma $\mathrm{qPCR}$ assay on blood samples and blood smears. J Med Microbiol 2010, 59(11):1285-1292.

17. Criado-Fornelio A, Martinez-Marcos A, Buling-Sarana A, Barba-Carretero JC: Presence of Mycoplasma haemofelis, Mycoplasma haemominutum and piroplasmids in cats from southern Europe: a molecular study. Vet Microbiol 2003, 93(4):307-317.
18. Altschul SF, Gish W, Miller W, Myers EW, Lipman DJ: Basic local alignment search tool. J Mol Biol 1990, 215(3):403-410.

19. Saitou N, Nei M: The neighbor-joining method: a new method for reconstructing phylogenetic trees. $\mathrm{Mol}$ Biol Evol 1987, 4(4):406-425.

20. Kimura M: A simple method for estimating evolutionary rates of base substitutions through comparative studies of nucleotide sequences. J Mol Evol 1980, 16(2):111-120.

doi:10.1186/1746-6148-8-55

Cite this article as: Barker et al: Haemoparasites of free-roaming dogs associated with several remote Aboriginal communities in Australia. BMC Veterinary Research 2012 8:55.

\section{Submit your next manuscript to BioMed Central and take full advantage of:}

- Convenient online submission

- Thorough peer review

- No space constraints or color figure charges

- Immediate publication on acceptance

- Inclusion in PubMed, CAS, Scopus and Google Scholar

- Research which is freely available for redistribution 